\title{
Total diz artroplasti revizyon cerrahisinde ameliyat öncesi planlama
}

\section{Preoperative planning for revision surgery of total knee arthroplasty}

\author{
Olcay Güler ${ }^{1}$, Mehmet Halis Çerci², Mahir Mahiroğulları ${ }^{1}$ \\ ${ }^{1}$ İstanbul Medipol Üniversitesi Tıp Fakültesi Ortopedi ve Travmatoloji Anabilim Dalı, İstanbul \\ ${ }^{2}$ Özel Nisa Hastanesi Ortopedi ve Travmatoloji Kliniği, İstanbul
}

\begin{abstract}
Diz artroplastisi revizyonu öncesi yapılacak planlamada amaç, cerrahinin kalitesini ve başarısını, dolayısıyla hasta memnuniyetini arttırmak olmalıdır. Ayrıntılı anamnez ve radyolojik inceleme sonrasında, ameliyat sürecini etkileyebilecek her konuyu standart bir metot ve algoritma içinde incelemek gerekir. Bütün bu hazırlıklar, cerrahın ameliyat sırasında karşılaşabileceği sorunlar ile ilgili daha seri ve doğru kararlar verebilmesini, verdiği kararın neden olabileceği sonuçları öngörebilmesini sağlar. Ameliyat öncesi fizik muayenede; cilt, periferik dolaşım, nörolojik durum, eklem hareket açıklığı ve eklem stabilitesi değerlendirilmelidir. Radyolojik incelemelerde, konvansiyonel diz anteroposterior lateral ve patellofemoral eklem tanjansiyel grafilerinin yanında, her iki alt ekstremite ortoröntgenogramların da incelenmesi gereklidir. Özellikle diz protez komponentlerinin rotasyonel malpozisyonlarında ve kemik defektlerinin değerlendirilmesi için, bilgisayarlı tomografi (BT) ile görüntüleme önem arz etmektedir. Hastanın mevcut diz protezinin markası, boyutu ve özellikleri, revizyon cerrahisi öncesi bilinmelidir. Ayrıca, grafiler ve ölçüm şablonları, revizyon cerrahisinde uygulanacak diz protezi özellikleri hakkında ön bilgi sahibi olmamızı kolaylaştırmaktadır. Mevcut implantların çıkartılması için gerekli ekipmanlar planlanmalı ve en kötü senaryoya göre hazırlık yapılmalıdır. Fizik muayene ve radyolojik incelemeler ışığında uygun revizyon diz protez seçeneklerine, kemik defektlerinin rekonstrüksiyonu için kemik greftlerine ve metal blok vb. desteklere ameliyat öncesi dönemde karar vermek, yüz güldürücü bir sonuç elde edilmesinde önemli rol oynar.
\end{abstract}

Anahtar sözcükler: total diz replasmanı; cerrahi düzeltme; ameliyat öncesi işlemler; planlama metodolojisi
The aim of preoperative planning before total knee arthroplasty (TKA) revision surgery should be increasing success and quality of surgery and patient satisfaction. All issues which have possible effects on treatment process should be evaluated in a standardized method and algorithm after detailed history, physical and radiological examination. By these preparations surgeon can give more accurate and quick decisions about the problems during the surgical operation and can foresee results of these decisions. Skin, peripheral vascular circulation, neurological situation, range of motion and stability of articulation should be evaluated while preoperative physical examination. In addition to standart standing knee anteroposterior/lateral, patellofemoral tangential X-rays, hip to ankle standing X-ray examinations should be evaluated while radiological examination. Computed tomography has a special importance especially for rotational malposition of implant components and bone defects adjacent to the implant. Brand, model, size and specificities of existing implants must be known before the revision surgery. Furthermore, the usage of X-rays and templates facilitates the collection of preliminary information about the specificities of the implants to be used while revision surgery. Necessary equipment must be acquired for implant removing and all preparations must be done by keeping in mind the worst scenario. Giving decisions on appropriate implant options and bone grafts, metallic augmentations for bone defect reconstruction, in the light of physical and radiological examination during the preoperative planning, plays an important role in achieving satisfactory results.

Key words: total knee replacement; surgical revision; preoperative proceedures; planning methodology

\section{GiRiş}

Primer total diz artroplasti (TDA) sonrasında çeşitli nedenlerle ve çeşitli sürelerde revizyon diz artroplastisi gerekebilmektedir. Revizyon TDA sonrasında da enfeksiyon, ekstansör mekanizma sorunları, aseptik gevşeme, periprostetik kırıklar, yara sorunları ve instabilite gibi komplikasyonlar sık görülmektedir. ${ }^{[1-3]}$ Rand ve arkadaşlarının 427 olgulu revizyon serilerinde, en sık tespit yetersizliğine bağlı revizyon yapılırken; anormal dizilim, komponent malpozisyonu, kırıklar ve patella problemleri diğer revizyon nedenleri olarak bildirilmiştir. ${ }^{[3]}$

- İletişim adresi: Prof. Dr. Mahir Mahiroğulları, İstanbul Medipol Üniversitesi Tıp Fakültesi Ortopedi ve Travmatoloji Anabilim Dalı, Atatürk Bulvarı No: 27 Unakapanı 34083 Fatih, İstanbul Tel: 0532 - 7791379 e-posta: mahirogullari@yahoo.com

- Geliștarihi: 8 Nisan $2015 \quad$ Kabul tarihi: 8 Nisan 2015 
Revizyon artroplasti cerrahisi, primer cerrahiye göre, hem cerrah hem de hasta için daha zahmetli bir süreçtir. Bu nedenle, revizyon cerrahisi öncesi yapılacak preoperatif planlama; cerrahinin kalitesini ve etkinliğini arttırmada, mevcut implantların çıkartılması için gerekli ekipmanın yeterli düzeyde temininde, yeniden uygulanacak olan implantların özellik ve boyutlarının tespitinde, cerrahın, ameliyatın başlangıcından sürecin bitimine kadar geçen süre ile ilgili zihinsel olarak hazır hale gelmesi ve bu sayede süreçteki aşamalarda karşılaşabileceği sorunlara daha hazırlıklı ve hızlı karar verebilir olmasında büyük önem arz eder. ${ }^{[4]}$

Bu makaledeki amacımız, revizyon TDA cerrahisinde, hastanın ameliyat öncesi planlaması ile ilgili güncel bilgileri gözden geçirmektir.

\section{AMELIYAT ÖNCESI DEĞERLENDIRME}

Öncelikle, ameliyat öncesi planlama sürecinde tespit edilen sorunlar ve riskler, hastaya cerrahi ve cerrahi sonrası dönemle ilgili sağlıklı ve doğru bilgiler verilmesinde önemlidir. Ameliyat öncesinde doğru bilgilendirme, hastanın gerçekçi beklentilere sahip olmasını ve bu sayede ameliyat sonrası tatmin düzeyinin yüksek olmasını sağlayacaktır. ${ }^{[4]}$

\section{Anamnez}

Anamnezde ilk adım, hastayı revizyona götüren nedenleri sorgulamak ve hastanın ağzından duymaktır. Hastanın ilk cerrahiden önceki durumu ile ilgili bilgiler de anamnezde mutlaka sorgulanmalı ve not alınmalıdır. Mevcut implantın üreticisi, tasarımı ve boyutları belirlenmelidir. Ĕger cerrahi sırasında implantın bir kısmına müdahale edilmeyecekse, bu bilgilere ulaşılması zorunludur. Cilt, vasküler yapılar ve nörolojik duruma ait sorgulamalar yapılmalıdır. Hastanın daha önceki yaralarının iyileşme süreci ile ilgili sorunlar mutlaka sorgulanmalıdır. Daha önce geçirilmiş venöz tromboemboli öyküsü olan hastalarda uygun ve yeterli profilaksi uygulanması, ameliyat öncesi ve ameliyat sonrası olası komplikasyonların önlenmesinde etkin rol oynamaktadır. Hastanın genel durumu, bütün bunlarla birlikte değerlendirilmelidir; beslenme, kooperasyon, oryantasyon ve psikolojik durumu da ameliyat öncesi incelenmelidir. ${ }^{[1,4,5]}$

\section{Fizik Muayene}

Fizik muayenede, ipsilateral kalça değerlendirilmeli ve hareket açıklığı ölçülmelidir. Kalça hareketleri ile diz şikayetlerindeki değişim değerlendirilmelidir. Yürüyüş analizi yapılmalı, omurga deformiteleri, kalça abduktorlarının fonksiyonu ve dinamik instabilite bulguları değerlendirilmelidir. ${ }^{[1,2,6]}$

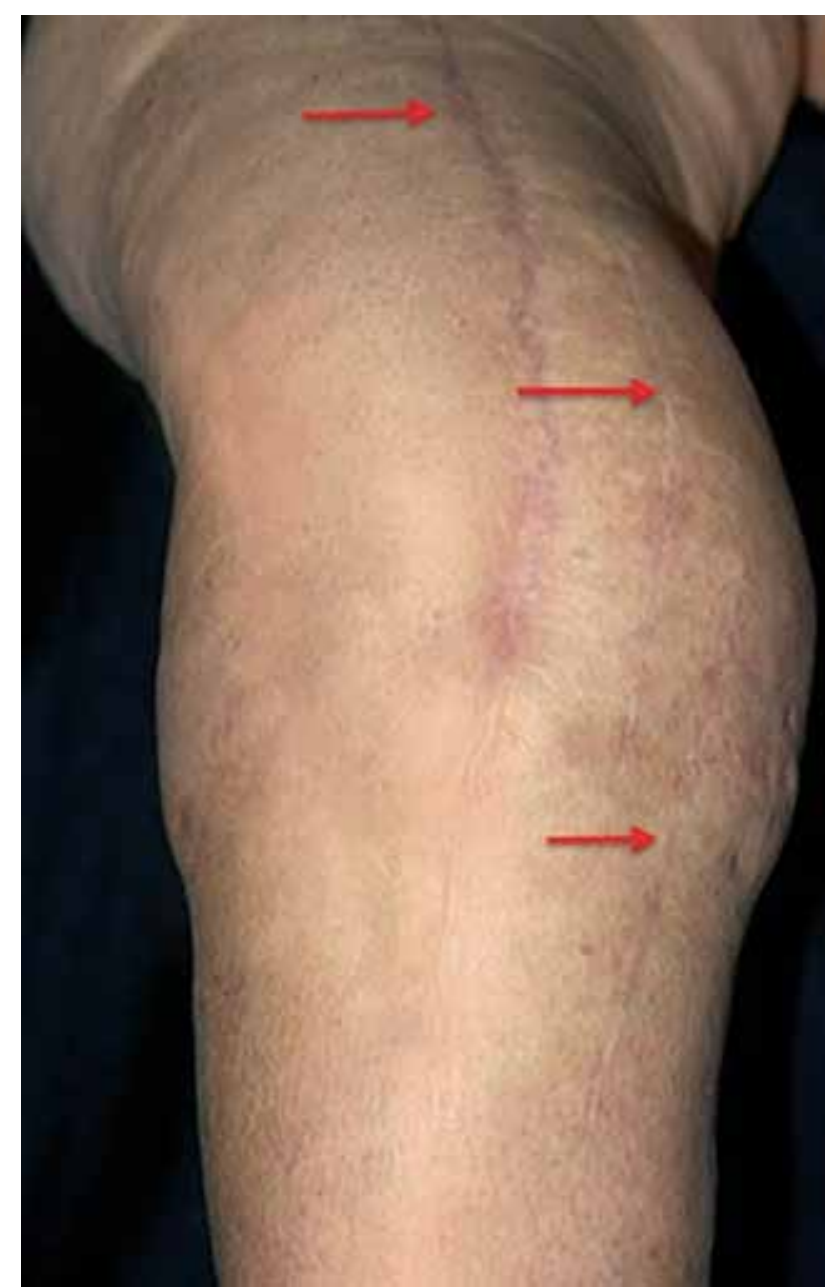

Şekil 1. Geçirilmiş cerrahilere bağlı, multipl cilt kesisi olan hastanın klinik görünümü. ${ }^{[7]}$

\section{Cilt Muayenesi}

Ciltte mevcut olan skarlar dikkatlice değerlendirilmelidir. Eğer orta hatta tek bir skar varsa, bunun kullanıması planlanmalı, birden fazla skar varsa cildin beslenmesi dikkate alınarak en lateral insizyon skarı bölgesi insizyon için planlanmalıdır (Şekil 1). İki insizyon arasındaki mesafenin $6 \mathrm{~cm}$ 'den daha fazla olması önerilmektedir. ${ }^{[7]}$ Transvers insizyon varlığında, yeni insizyon eskisine dik uygulanabilir Ancak, $60^{\circ}$ 'den az açılanma olmamalıdır. ${ }^{[1]}$ Değerlendirmede ciltle ilgili olası bir sorun düşünülecek olursa, ameliyat öncesi plastik cerrahi konsültasyonu önerilmektedir (Şekil 2. a, b). ${ }^{[7]}$

\section{Periferik Vasküler Değerlendirme}

Hastada ameliyat öncesi periferik vasküler patoloji araştırılması önem arz etmektedir. İnvaziv olmayan yöntemlerle ve transkutanöz oksimetriyle, diz bölgesindeki cildin iyileşmesiyle ilgili olası sorunlar ortaya 

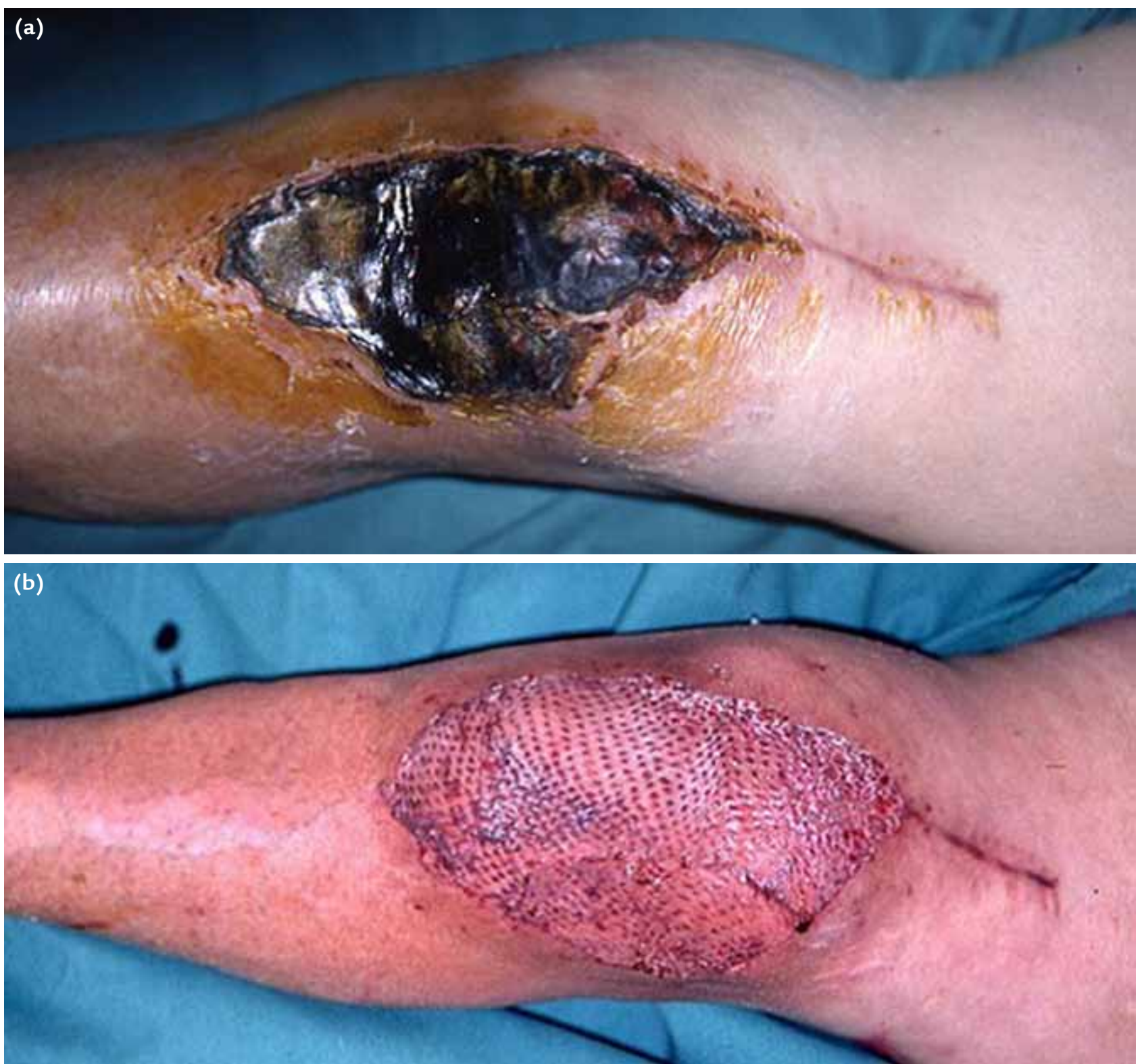

Şekil 2. a-b. Yetmiş iki yaşında bayan hastanın, revizyon diz protezi sonrası görülen cilt nekrozu (a). ${ }^{[11]}$ Latissimus dorsi kas serbest flebi ile yara kapatılması sonrası 2. ayda görünüm (b). ${ }^{[11]}$

konularak gerekli önlemler alınmalıdır. Cilt dolaşımından emin olmak için, şüpheli olgularda trankutanöz oksimetri ile diz çevresi cilt analizi yapılarak insizyon planlamalıdır. ${ }^{[8]}$ Turnike kullanılacaksa, basıncı gözden geçirilmeli ve periferik vasküler yapılara hasar verip vermeyeceği değerlendirilmelidir. Turnike basıncının 350 $\mathrm{mmHg}$ olmasının, $225 \mathrm{mmHg}$ basınca göre ciltte daha fazla hipoksiye neden olduğu bildirilmiştir. Ayrıca, turnike süresinin kısa olduğu ya da turnikenin hiç kullanılmadığı olgularda, yara iyileşme sorunun daha az olduğu tespit edilmiş̧tir (Şekil 3). ${ }^{[9]}$

\section{Nörolojik Durum}

Cerrahi öncesinde, nörolojik durumun tam olarak tespit edilerek ortaya konulduğuna emin olunmalıdır. Ameliyat öncesinde olası bir nörolojik hasar riski tespit edilirse, özellikle ciddi fleksiyon kontraktürü ve/veya valgus deformitesi durumunda, cerrahideki düzeltme ile peroneal sinir hasarı oluşabileceği akılda tutulmalıdır. ${ }^{[10]}$ Ayrıca, turnike süresinin 180 dakikanın altında tutulmasının, ameliyat sonrası nörolojik komplikasyonların riskini azalttığı bildirilmiştir. ${ }^{[1]} \mathrm{Bu}$ gibi durumlarda, ameliyat sonrasında nörolojik durumun 


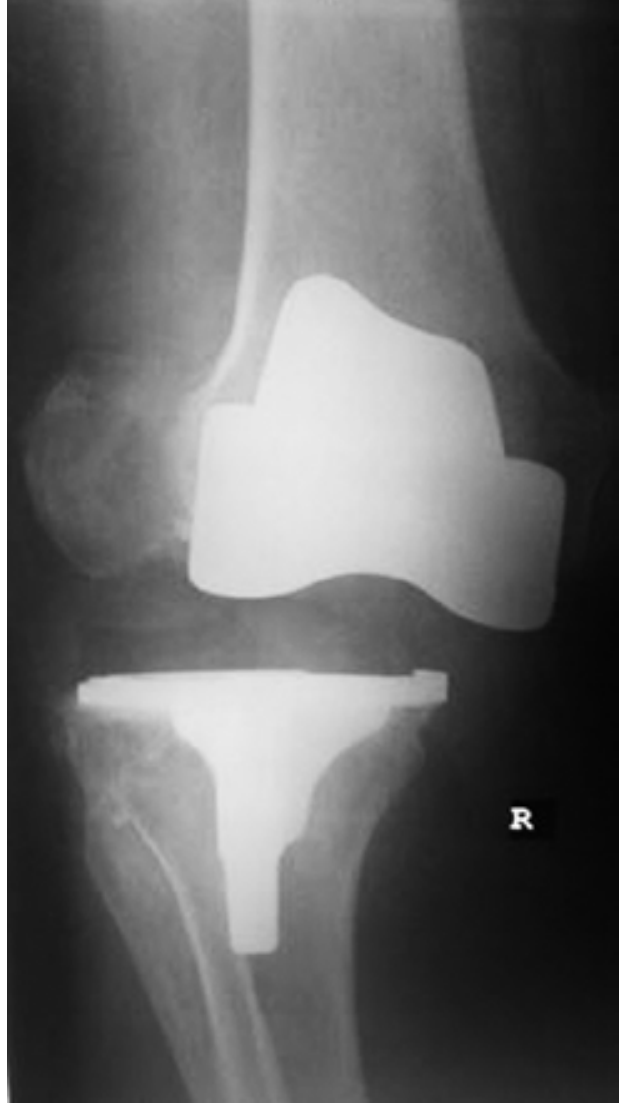

Şekil 3. Yetmiş beş yaşındaki bayan hastada, sağ diz TEP ardından ameliyat sonrası 5. yılda ortaya çıkan instabiliteyi gösteren grafi.

değerlendirilmesini geciktirebilecek uzun süreli sinir blokları ve bölgesel anesteziden kaçınılmalı, ameliyat sonrası dönemde dizin nörolojik durumu değerlendirilene kadar diz fleksiyonda tutularak, aşamalı olarak ekstansiyona alınması planlanmalıdır. ${ }^{[4]}$

\section{Eklem Hareket Açıklığı}

Hastaların ameliyat öncesi hareket açıklıkları, ameliyat sonrası hareket açıklığını belirleyen önemli etmenlerden biridir. Enfeksiyona ve artrofibrozise bağlı fleksiyon kısıtlılığı olan hastalarda, cerrahi girişim sırasında, ekstansör kaslarda yaralanma ve tuberositas tibiadan patellar tendon avulsiyonlarına karşı dikkatli olmak gerekir. ${ }^{[1,5]}$ Distalde tuberositas tibia osteotomisi, proksimalde ise kuadriseps uzatma yöntemleri, ekstansör mekanizma yaralanmasını önlemek amacıyla önerilen cerrahi tekniklerdir. ${ }^{[1,5]}$

\section{Stabilitenin Değerlendirilmesi}

Ameliyat öncesi kollateral bağların değerlendirilmesi, kısıtlayıcı implant kullanılması ve rekonstrüksiyonlar açısından önemlidir. Fizik muayenede, ekstansiyonda, midfleksiyonda ve $90^{\circ}$ fleksiyonda varus-valgus testleri yapılmalıdır. Midfleksiyondaki değerlendirme, tam ekstansiyonda stabilizatör etki gösteren posterior kapsülü gevşettiği için, mediyal ve lateral-kollateral bağ yetmezliğini izole etmede önemlidir (Şekil 1). Fleksiyon instabilitesinin değerlendirilmesi açısından, $90^{\circ}$ fleksiyonda yapılan muayene de aynı derecede önemlidir. Hastanın yürüyüşü esnasında; dizdeki kaymalar, açılanmalar mutlaka değerlendirilmeli ve rotatuvar instabiliteler aranmalıdır. Merdiven inip çıkarken, çömelme sırasında veya diz fleksiyonu sırasında olan ağrı, ön diz bölgesinde özellikle pes anserinus kısmında olan hassasiyet veya $90^{\circ}$ 'de tibianın öne translasyonunda artış ile kombine olan semptomlar, güçlü bir şekilde fleksiyon instabilitesini akla getirir. ${ }^{[5,12]}$

Cerrah, dizin tüm eklem hareketi boyunca patellanın hareketini ve femurun troklear oluğuna göre stabilizasyonunu ve pozisyonunu dikkatlice değerlendirmelidir. Patellar klunk sendromu, diz fleksiyondan ekstansiyona alınırken, yaklaşık $30-45^{\circ}$ civarında gözlemlenir ve patellanın palpe edilebilir hatta duyulabilir bir kliği ile birliktedir. ${ }^{[13]}$ Ekstansör mekanizmanın güç ve bütünlügünü, aktif ve pasif hareketlerde değerlendirmek de önemlidir. Bu değerlendirme, cerrahın, tam ekstansiyon kısıtlılığının fleksiyon kontraktüründen mi yoksa ekstansör mekanizmanın yetersizliğinden mi olduğu konusunda emin olmasını sağlar; bu da, ekstansör mekanizma işlev bozukluğunun etiyolojisini tanımlamada önemlidir. Ek olarak, kuadriseps kasının gücü ve patellar instabilite olgularında ise vastus mediyalis oblikus özellikle değerlendirilmelidir. ${ }^{[5,12]}$

\section{RADYOLOJIK INCELEME}

Radyolojik değerlendirme, ameliyat öncesi planlamanın önemli basamaklarından biridir. Anamnezin radyografilerle kombinasyonu ile, mevcut implantla ilgili sorun tam olarak tespit edilmiş olur ve böylece, revizyon cerrahisi sırasında çözülmesi gereken sorun da ortaya konulur. Radyografiler üzerinde ameliyat öncesi dönemde yapılan çalışmalar ile, mevcut mekanik akstaki sorunlar ortaya konulabilir ve doğru aksın yeniden sağlanması için tibia ve femurdan yapılması gereken kesiler, cerrahiden önce kalıplar ile hesaplanabilir. Bu hesaplamalara göre, gerekli olabilecek implant tipleri ve greftler cerrahi öncesinde tahmin edilebilir. ${ }^{[1,2,4,5]}$

Ayakta basarak anteroposterior ve lateral grafiler çekilmelidir. Ameliyat öncesi planlamada, genellikle her iki alt ekstremite ortoröntgenogramı gerekir. Bağ yetmezliği ve instabilite şüphesi olan olgularda, stres grafileri tanıda yardımcı olacaktır. Floroskopi 

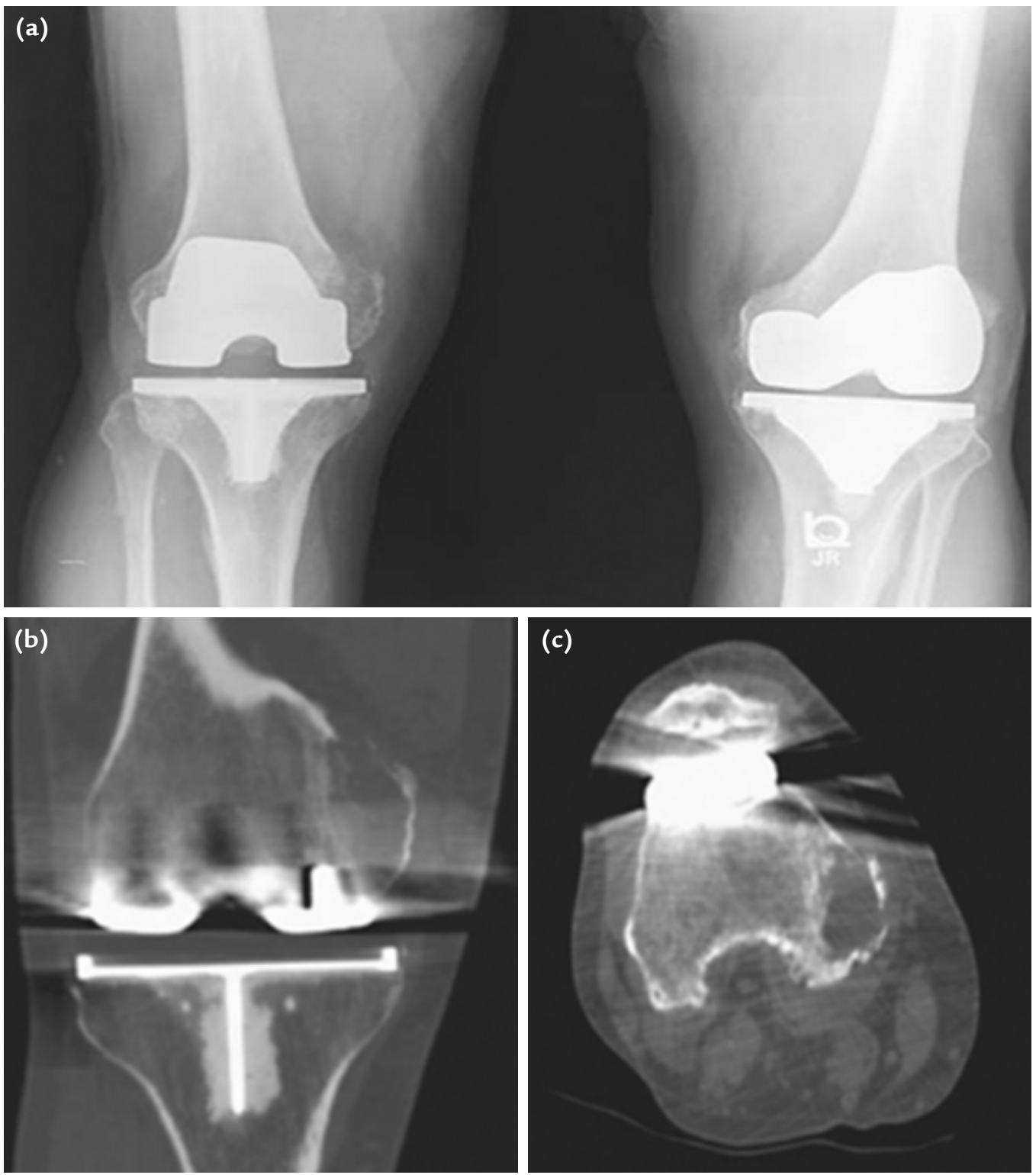

Şekil 4. a-c. Altmış dört yaşında bayan hastanın her iki diz grafisi (a); koronal (b) ve aksiyel (c) BT tetkikinde, osteolizis ve mediyal kondilde patolojik kırık görünümü. ${ }^{[4]}$

pozisyonunda çalışılan grafiler, implant arayüzünün tanjansiyel görüntüsünü elde etmede çok başarılıdır ve implantın tespiti ile ilgili bilgi verir. ${ }^{[4]}$ Femoral ve tibial kısımların rotasyonel pozisyonları BT ile değerlendirilmelidir (Şekil 4 ve 5). Rotasyonel deformiteler, patellar komplikasyonlar, instabilite ve eklem sertliğinde önemli yer tutmaktadır. ${ }^{[14]}$

Patellofemoral patolojilerde, tanjansiyel grafiler de ayrıntılı olarak değerlendirilmelidir. Eğer grafilerde asıl sorunun patellofemoral eklem olduğu düşünülürse, BT ile değerlendirme yapıımalıdır (Şekil 6). ${ }^{[4]}$

\section{IMPLANT ÇIKARTMA HAZIRLIĞI}

Ameliyat öncesi planlamanın belirlediği en önemli bölümlerden biri implantın çıkartılmasıdır. Mevcut implantın, markası, tipi ve boyutunun ameliyat öncesinde tespiti çok önemlidir. İmplantlar radyolojik olarak değerlendirildiğinde, marka ve tipi tespit edilmiş olsa da, aynı marka ve tipin bazı kısımlarında küçük farklılıklar olabileceği akılda tutulmalıdır. Cerrahi sırasında implantın bir kısmına müdahale edilmeyecekse, marka ve tipinin bilinmesi son derece önemlidir. Çünkü, müdahale edilen kısımlara uygulanacak yeni 


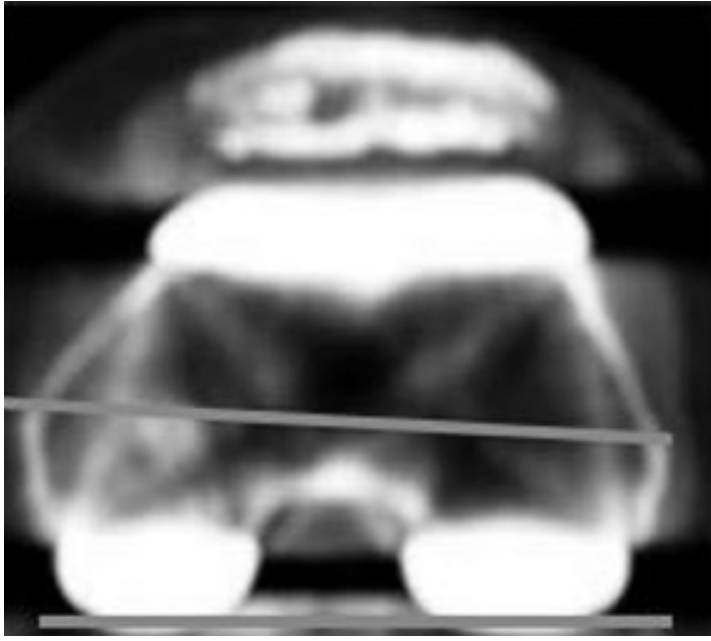

Şekil 5. Femoral komponentin internal rotasyonunu gösteren BT kesiti. ${ }^{[4]}$

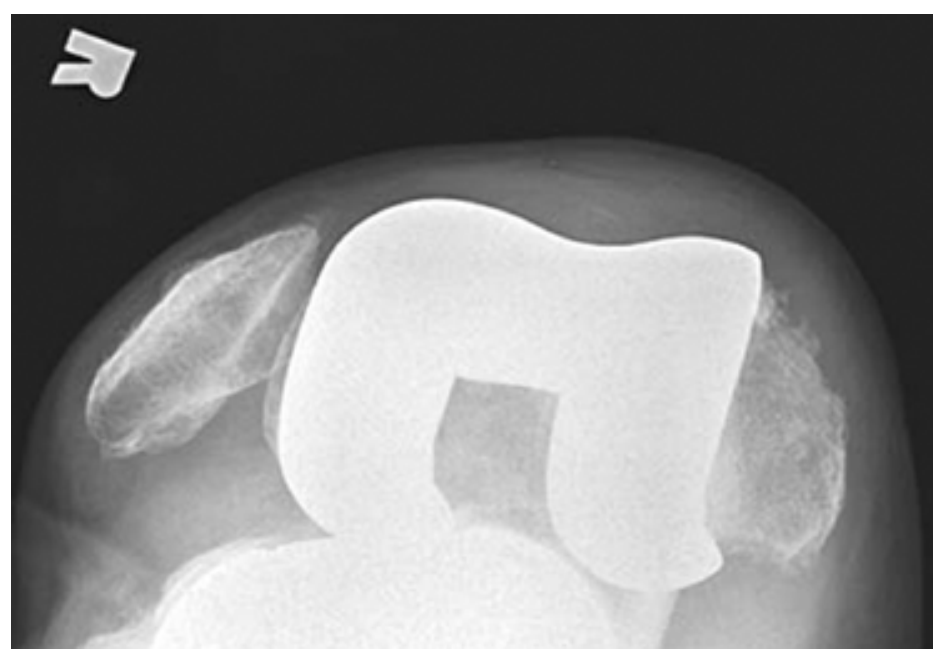

Şekil 6. Patella tanjansiyel grafisinde patellanın dislokasyon görüntüsü. ${ }^{[4]}$ parçaların mutlaka diğer kısımlarla uyumlu olması gerekir. Ayrıca, model ve tipin önceden bilinmesi, cerrahın ameliyat öncesinde implanta özgü çıkartma aletlerini istemesini ve bu modele özgü olabilecek çıkartma teknikleri hakkında bilgilenmesini sağlar. Polietileni tibial komponentten ayırmak için, önceki implanta ait spesifik polietilen çıkarıcılar gerekir; komponentleri çıkarmak için ise, osteotomlar, ince testereler ve mikrotestere bıçakların ameliyat öncesi dönemde hazırlanması önemlidir. ${ }^{[1,4-6]}$

\section{AMELIYAT ÖNCESI KEMIK KAYBININ DEĞERLENDIRILMESI VE ŞABLON UYGULAMASI}

Kemik kaybının bölgesi, ciddiliği ve geometrisi değerlendirilmelidir. Konvansiyonel grafiler ile kemik defektleri değerlendirilebilmektedir. Ayrıca, BT ile, protez çevresindeki kemik kaybının düz grafiye göre daha ayrıntılı olarak gösterildiği bildirilmiştir. ${ }^{[15]}$ Planlanan implantın pozisyonu ve boyutları, cerrahi öncesinde şablonlar ile tespit edilebilir. Şablonlar, aynı zamanda, kemik dokudaki kayıpların cerrahi süreçteki yönetiminin önceden planlanmasında kullanılabilir (Şekil 7, 8). Ameliyat öncesi planlamada, en kötü senaryoya hazır olunmalıdır. Komponentler çıkarıldıktan sonra ortaya çıkabilecek kemik defektleri için, allogreftler, metal augmentler ve stemler hazırlanmalıdır. Revizyon diz protezinde implant tespiti; kemik yüzeyi, metafiz ve diyafiz olmak üzere, üç bölgeden yapılmaktadır. Epifizde kemik yüzeye çimento, metafizyel defektlerde ise metal augmentler ve kemik greftleri ile uygulama yapılır; diyafizyel tespit ise, sementli ya da press-fit uygulanan stemlerle sağlanır. ${ }^{[1,2,4,5]}$

\section{FLEKSIYON-EKSTANSIYON DENGESININ SAĞLANMASI}

Son zamanlarda, fleksiyon-ekstansiyon dengesinin sağlanması ile eklem çizgisi restorasyonunun birbirlerini destekleyen ayrıcalıklı konular olduğu anlaşılmaktadır. Bu nedenle, cerrahi öncesinde fleksiyon-ektansiyon dengesi sağlanması ile aynı anda eklem çizgisi restorasyonu da planlanmalıdır. Ameliyat öncesi radyografilerde, posterior femoral kemik kaybı ve distal femoral kemik kaybı değerlendirilmelidir. Posterior femoral kemik kaybının fazla olması, cerrahi sırasında fleksiyon boşluğunun doldurulması için daha fazla posterior femoral onarım gerekeceği anlamına gelir. ${ }^{[1,4,12]}$

\section{EKLEM ÇIZGI RESTORASYON DEĞERLENDIRILMESi}

Revizyon cerrahisinin önemli hedeflerinden birisi de eklem seviyesini restore etmektir. ${ }^{[16,17]}$ Eklem seviyesinin yüksek olması ameliyat sonrası dönemde patella baja ve fleksiyon kısıtlılığına, eklem seviyesinin düşük olması ise patella alta ve uyum bozukluğuna neden olur. $^{[5]}$ Bu nedenle, ameliyat öncesi planlamada çekilecek radyografilerle analiz ve gerekirse karşı dizden ölçümler alınarak eklem çizgisi planlaması yapılmalıdır. Eklem çizgisinin femoral lateral epikondilden 2,5 $\mathrm{cm}$ distalde, mediyal epikondilden $3 \mathrm{~cm}$ distalde ve fibula başından ise 1,5-2 cm proksimalde olduğunu belirten yayınlar mevcuttur. ${ }^{[1,12]}$ Az sayıda olgu içeren bir çalışmada sağlam dizlerde yapılan ölçümlerde, transepikondiller çizgi ile eklem çizgisi arasındaki mesafenin transepikondiller aks genişliği ile doğru orantılı olduğu bildirilmiş ve gerçek eklem çizgisinin 


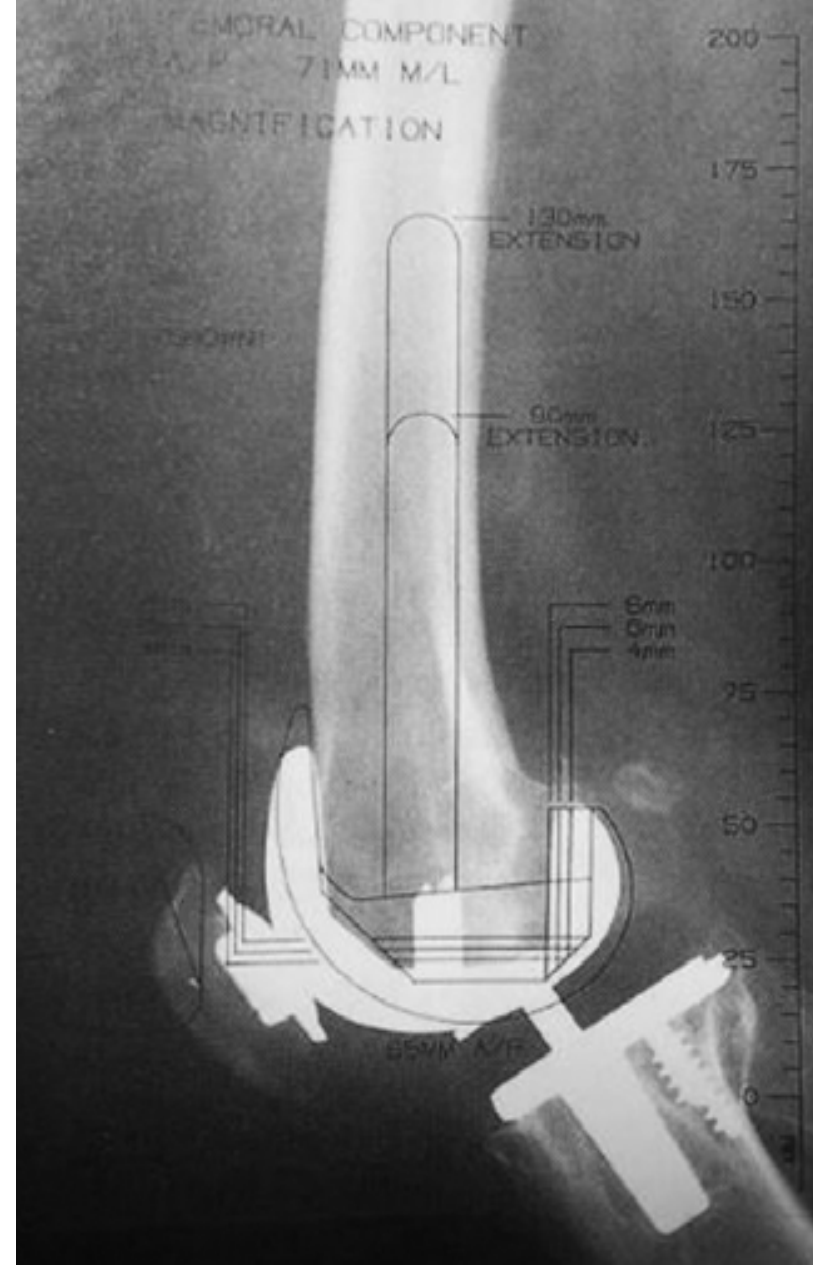

Şekil 7. Femoral komponentin revizyon öncesi şablon ile ölçümü..[2]

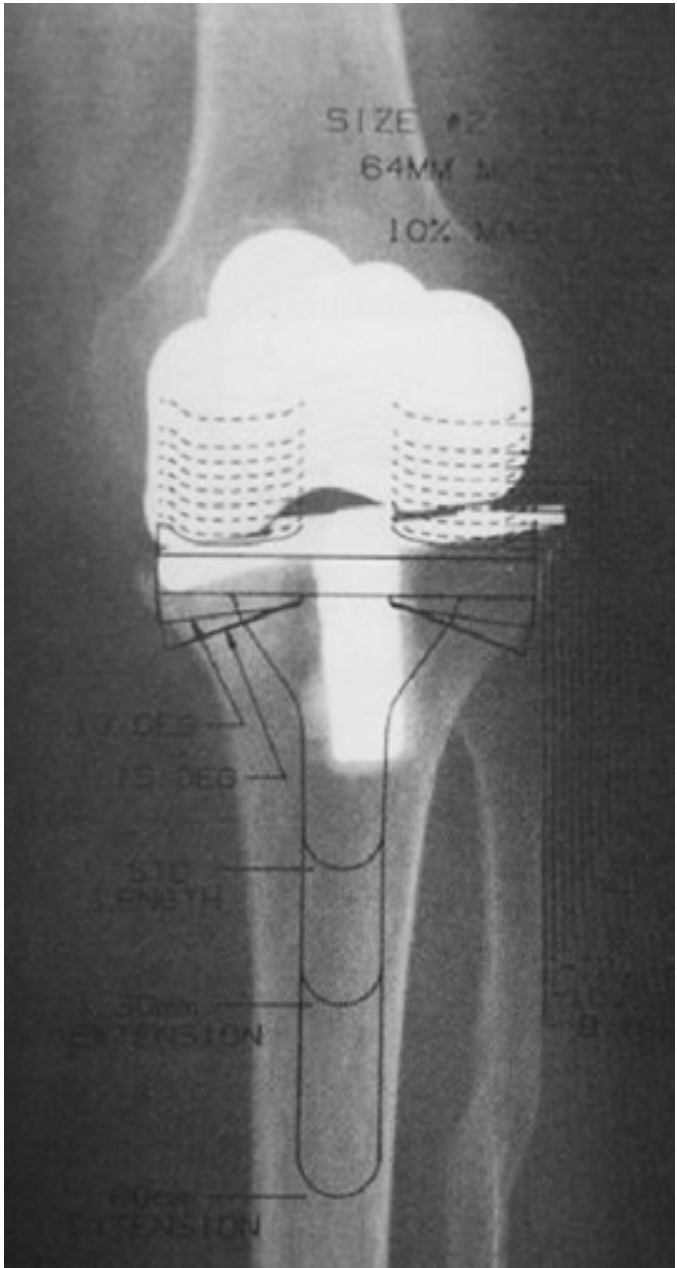

Şekil 8. Tibial komponentin revizyon öncesi şablon ile ölçümü..[2] belirlenebilmesi için transepikondiller aks genişliği ölçümü önerilmiştir. ${ }^{[18]}$

\section{IMPLANT SEÇIMi}

TDA revizyonunun komplike bir cerrahi yöntem olmasından dolayı, çok farklı implant seçenekleri hazırlanması gerekir. ${ }^{[2]}$ Revizyon implantlar arasında; arka çapraz bağı koruyan/kesen implantlar, valgus-varusu kısıtlayıcı implantlar ve rotasyon menteşeli implantlar sayılabilir. ${ }^{[2]}$ Revizyon cerrahisinde amaçlardan birisi de, en az kısıtlayıcı implant kullanarak yeterli stabilite sağlamaktır. Çünkü varus-valgus kısıtlayıcı ve rotasyon menteşeli implantlarda, implant-çimento-kemik bölgesinde ortaya çıkan stres artışına bağlı, erken dönemde gevşeme ve radyolusen hatlar görüldügü bildirilmiştir. ${ }^{[2,19]}$ Mediyal ve lateral-kollateral bağ instabilitesi mevcut olan hastalarda, kısıtlayıcı implantlar kullanılmaktadır. ${ }^{[5]}$

\section{SONUÇ}

Total diz protez revizyonunda başarının anahtarı, öncelikle, revizyona götüren etiyolojinin tespit edilmesinden geçer. Ayrıntılı anamnez ve radyolojik inceleme sonrasında, ameliyat sürecini etkileyebilecek her konuyu belirli bir metot ve düzen içinde incelemek gerekir (Tablo 1). ${ }^{[6]}$ Hastaların genel durumunun yanında, eşlik eden hastalıkların da değerlendirilmesi önem arz etmektedir. Önceki proteze ait bilgilerin elde edilmesi, revizyon protez seçeneklerinin ve olası kemik defektlerinin rekonstrüksiyonu için gereken malzemenin hazırlanmasında kolaylık sağlar. Bütün bu hazırlıklar, cerrahın, ameliyat sırasında karşılaşabileceği sorunlar ile ilgili daha seri ve doğru kararlar verebilmesini, verdiği kararın neden olabileceği durumları öngörebilmesini ve cerrahi sırasında düşünmek için daha kısa aralar verebilmesini sağlar. ${ }^{[4]}$ 
Tablo 1. Total diz artroplasti revizyonu planlaması için hasta formu ${ }^{[6]}$

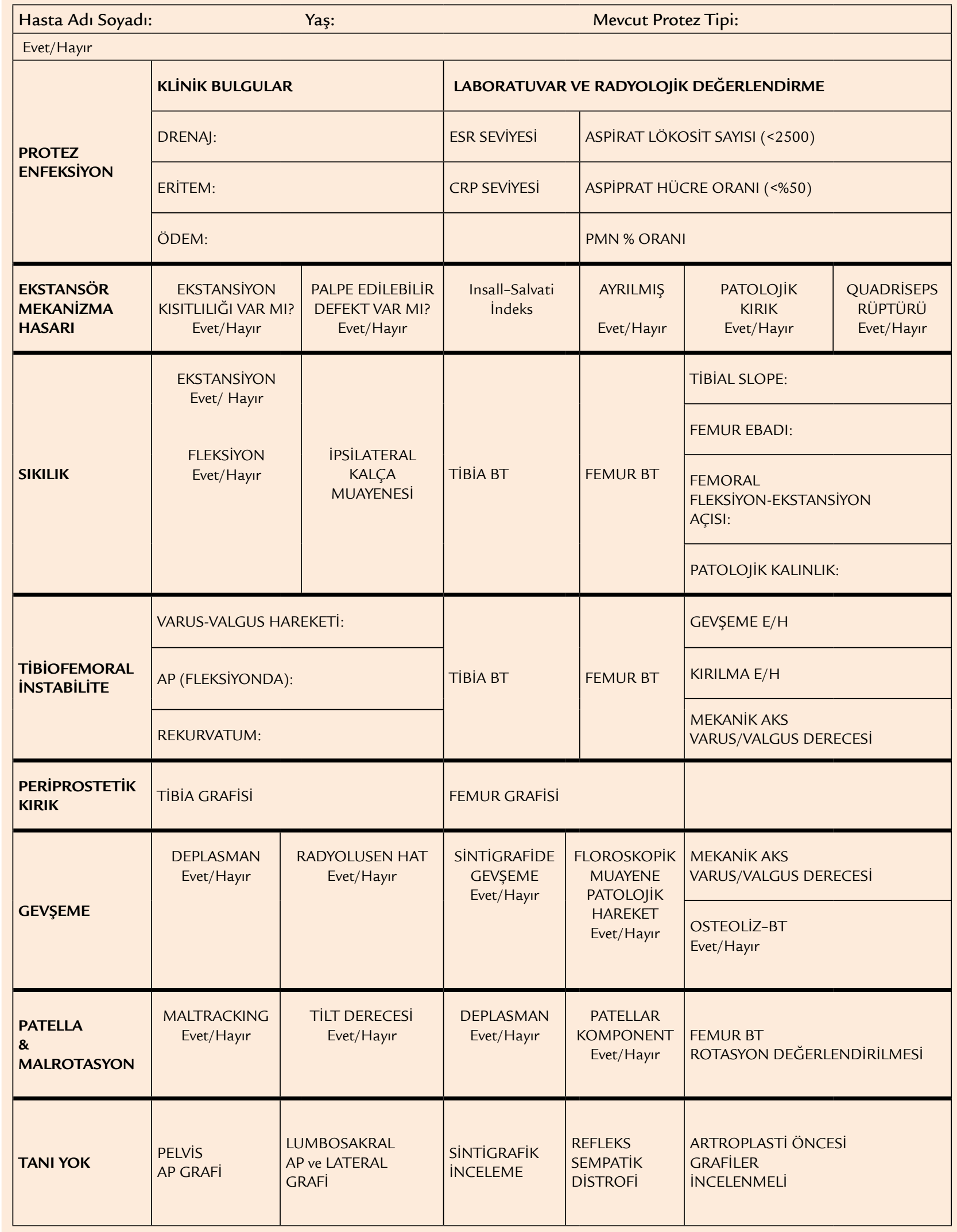




\section{KAYNAKLAR}

1. Nett MP. Scuderi GR. Revision of Aseptic Failed Total Knee Arthroplasty. In: Scott WN, editor. Insall \& Scott Surgery of the Knee. Philadelphia, PA, USA: Elsevier Churchill Livingstone; 2012. p.1327-45.

2. Gustke KA. Preoperative planning for revision total knee arthroplasty: avoiding chaos. J Arthroplasty 2005;20(4 Suppl 2):37-40.

3. Rand JA, Peterson LF, Bryan RS, Ilstrup DM. Revision total knee arthroplasty. Instr Course Lect 1986;35:305-18.

4. Berry DJ. Preoperative planning for revision total knee arthroplasty. In: Callaghan JJ, editor. The Adult Knee, 1st ed. Philadelphia, PA: Lippincott Williams \& Wilkins; 2003. p.1413-9.

5. Meneghini RM. Revision Total Knee Artroplasty. In: Glassman AH, Lachiewicz PF, Tanzer M, editors. Orthopaedic Knowledge Update (OKU-4), Hip and Knee Reconstruction. Rosemont, Ill.: American Academy of Orthopaedics Surgeons (AAOS); 2011. p.165-76.

6. Vince KG. Bedard M. Implanting the Revision Total Knee Arthroplasty. In: Lotke PA, Lonner J, editors. Master Techniques in Orthopaedic Surgery: Knee Arthroplasty, 3rd ed. Baltimore, MD: Lippincott Williams \& Wilkins; 2008. p.203-28.

7. Sanna M, Sanna C, Caputo F, Piu G, Salvi M. Surgical approaches in total knee arthroplasty. Joints 2013;1(2):34-44.

8. Aso K, Ikeuchi M, Izumi M, Kato T, Tani T. Transcutaneous oxygen tension in the anterior skin of the knee after minimal incision total knee arthroplasty. Knee 2012;19(5):576-9. CrossRef

9. Clarke MT, Longstaff L, Edwards D, Rushton N. Tourniquetinduced wound hypoxia after total knee replacement. J Bone Joint Surg Br 2001;83(1):40-4.

10. Schinsky MF, Macaulay W, Parks ML, Kiernan H, Nercessian OA. Nerve injury after primary total knee arthroplasty. J Arthroplasty 2001;16(8):1048-54.
11. Horlocker TT, Hebl JR, Gali B, Jankowski CJ, Burkle CM, Berry DJ, Zepeda FA, Stevens SR, Schroeder DR. Anesthetic, patient, and surgical risk factors for neurologic complications after prolonged total tourniquet time during total knee arthroplasty. Anesth Analg 2006;102(3):950-5.

12. Mihalko WM. Arthroplasty of the Knee. In: Canale ST, Beaty $\mathrm{JH}$, editors. Campbell's Operative Orthopaedics. 12th ed. Canada: Elsevier; 2013. p.376-444.

13. Clarke HD, Fuchs R, Scuderi GR, Mills EL, Scott WN, Insall $\mathrm{JN}$. The influence of femoral component design in the elimination of patellar clunk in posterior-stabilized total knee arthroplasty. J Arthroplasty 2006:21(2):167-71.

14. Berger RA, Crossett LS, Jacobs JJ, Rubash HE. Malrotation causing patellofemoral complication after total knee arthroplasty. Clin Orthop Relat Res 1998;(356):144-53.

15. Reish TG, Clarke HD, Scuderi GR, Math KR, Scott WN. Use of multi-detector computed tomography for the detection of periprosthetic osteolysis in total knee arthroplasty. J Knee Surg 2006;19(4):259-64.

16. Yoshii I, Whiteside LA, White SE, Milliano MT. Influence of prosthetic joint line position on knee kinematics and patellar position. J Arthroplasty 1991;6(2):169-77.

17. Selvarajah E, Hooper G. Restoration of the joint line in total knee arthroplasty. J Arthroplasty 2009;24(7):1099-102. CrossRef

18. Romero J, Seifert B, Reinhardt O, Ziegler O, Kessler O. A useful radiologic method for preoperative joint-line determination in revision total knee arthroplasty. Clin Orthop Relat Res 2010;468(5):1279-83. CrossRef

19. Hartford JM, Goodman SB, Schurman DJ, Knoblick G. Complex primary and revision total knee arthroplasty using the condylar constrained prosthesis: an average 5 -year followup. J Arthroplasty 1998;13(4):380-7. 